\title{
Calibration of the rutting model in HDM 4 on the highway network in Macedonia
}

\author{
Slobodan Ognjenovic ${ }^{1, *}$, Vladimir Okrepilov ${ }^{2}$, Riste Ristov ${ }^{3}$, Jovan Papic ${ }^{4}$ \\ ${ }^{1}$ Ss. Cyril and Methodius University in Skopje, Faculty of Civil Engineering, blvd. Partizanski Odredi \\ 24,1000 Skopje, Republic of Macedonia \\ ${ }^{2}$ Federal State Budgetary Institution of Science Institute of Regional Economic Problems of the \\ Russian Academy of Sciences, 190003, Serpuhovskaya st.,38, St. Petersburg, Russia \\ ${ }^{3}$ Prostor DOO-Kumanovo, Mosa Pijade 2, 1300 Kumanovo, Republic of Macedonia \\ ${ }^{4}$ Ss. Cyril and Methodius University in Skopje, Faculty of Civil Engineering, blvd. Partizanski Odredi \\ 24,1000 Skopje, Republic of Macedonia
}

\begin{abstract}
The World Bank HDM 4 model is adopted in many countries worldwide. It is consisted of the developed models for almost all types of deformation on the pavement structures, but it can't be used as it is developed everywhere in the world without proper adjustments to local conditions such as traffic load, climate, construction specificities, maintenance level etc. This paper presents the results of the researches carried out in Macedonia for determining calibration coefficient of the rutting model in HDM 4.
\end{abstract}

\section{Introduction}

This research was carried out in the period from 2010 until 2014 on a number of sections of the highway network in Macedonia, such as Veles-Gradsko, Gradsko-Negotino and Kumanovo-Miladinovci in total length of around $100 \mathrm{~km}$.

The purpose of the research was to provide initial calibration coefficient of the rutting model on the highway network in Macedonia. The data used for the research was provided by regular measurement in the period from 2002 to 2006 and from 2010 to 2014. It should be noted that no significant maintenance activities were taken in the period from 2006 to 2010. The paper presents the results of the calibration of the rutting model in HDM4 [1-8].

\section{Description of rutting development model}

According to HDM-4 the rutting model consists of the following components:

- Initial thickening

- Structural deformation

- Plastic deformation

- Wear and tear due to use of winter tyres

* Corresponding author: ognjenovic@gf.ukim.edu.mk 
In most cases, only the first three components of the rutting development are taken into account, because there are, usually no data on the influence of winter tyres on the appearance of rutting.

\section{Initial thickening}

Initial thickening is given in the following equation:

$$
\mathrm{RDO}=\mathrm{K}_{\text {rid }}\left\lfloor\mathrm{a}_{0} \cdot\left(\mathrm{YE} 4 \cdot 10^{6}\right)^{\left(\mathrm{a}_{1}+\mathrm{a}_{2} \cdot \mathrm{DEF}\right)} \cdot \mathrm{SNP}^{\mathrm{a}_{3}} \cdot \mathrm{COMP}^{\mathrm{a}_{4}}\right\rfloor
$$

RDO- rutting caused by initial thickening [mm]

$\mathrm{K}_{\text {rid }}$ - calibration coefficient for a certain initial thickening

YE4- average annual number of equivalent standard axes [million/lane]

DEF- average annual deflection [mm]

SNP- modified structural number of the pavement

COMP- relative compacting $(\%)$ (Table 1$)$

$\mathrm{a}_{i}$ - model coefficients

Table 1. Recommended values of the relative compacting level COMP

\begin{tabular}{|l|c|}
\hline \multicolumn{1}{|c|}{ Compactness } & Relative compactness COMP [\%] \\
\hline Total compactness in all layers & 100 \\
\hline Total compactness in some layers & 95 \\
\hline Adequate compactness in most layers & 90 \\
\hline Inadequate compactness in most layers & 85 \\
\hline
\end{tabular}

What is of special importance is the relation between the advancement of the initial rutting and the standard deviation. Currently, HDM-4 enables for positive linear relation between the rutting and the resulting standard deviation of the rutting depth. It is considered that this trend can be negative in the initial stages of thickening.

Table 2. Values of the coefficient of the model of initial thickening of pavements without creation of cracks.

\begin{tabular}{|c|c|c|c|c|}
\hline $\mathbf{a} 0$ & $\mathbf{a} 1$ & $\mathbf{a} 2$ & $\mathbf{a 3}$ & $\mathbf{a} 4$ \\
\hline 51740 & 0.09 & 0.0384 & -0.502 & -2.30 \\
\hline
\end{tabular}

\section{Structural information}

Rutting is a very good indicator of the pavement structure condition. For example, on the world level, rutting is one of the key indicators of the condition that is used in the road maintenance contracts. It is supposed that the appearance of rutting in the road network shall gain importance in future, receiving increased understanding of the condition.

HDM -4 gives two forms of rutting progress on cracked and non-cracked sections:

- Structural deformation on no-cracked sections

$$
\operatorname{RDST}_{\mathrm{UC}}=\mathrm{K}_{\mathrm{rst}} \cdot\left(\mathrm{a}_{0} \cdot \mathrm{SNP}^{\mathrm{a}_{1}} \cdot \mathrm{YE}^{\mathrm{a}_{2}} \cdot \mathrm{COMP}^{\mathrm{a}_{3}}\right)
$$

- $\quad$ Structural deformation after the incurrence of cracks

$$
\operatorname{RDST}_{\mathrm{CRK}}=\mathrm{K}_{\mathrm{rst}} \cdot\left(\mathrm{a}_{0} \cdot \mathrm{SNC}^{\mathrm{a}_{1}} \cdot \mathrm{YE}^{\mathrm{a}_{2}} \cdot \mathrm{MMP}^{\mathrm{a}_{3}} \cdot \mathrm{ACX}^{\mathrm{a}_{4}}\right)
$$


$\triangle \mathrm{RDST}$ - gradual increase of the structural deformation in the year of analysis [mm]

$\mathrm{K}_{r s t}$ - coefficient of calibration for a structural deformation

YE4- annual number of equivalent standard axes [million/lane]

COMP- relative compacting [\%]

MMP- average monthly precipitations [ $\mathrm{mm} / \mathrm{month}]$

SNC- modified structure number of the pavement

ACX- area of non-indexed cracks [\% from the total lane of traffic lane]

$\mathrm{a}_{i}$ model coefficients

Ако $\mathrm{ACX}_{\mathrm{a}}=0 \Rightarrow \Delta \mathrm{RST}=\Delta \mathrm{RST}_{\mathrm{uc}}$

Ако $\mathrm{ACX}_{\mathrm{a}}>0 \Rightarrow \Delta \mathrm{RST}=\Delta \mathrm{RST}_{\mathrm{uc}}+\Delta \mathrm{RST}_{\mathrm{crk}}$

$\Delta \mathrm{RST}_{\mathrm{uc}}$ - increase of rutting due to structure deformation on non-cracked pavements [mm]

$\Delta \mathrm{RST}_{\mathrm{crk}}$ - increase of rutting due to structure deformation on cracked pavements [mm]

Table 3. Values of the coefficients of the structure deformation model

\begin{tabular}{|l|c|l|l|l|l|}
\hline Pavement condition & $\mathrm{a}_{0}$ & $\mathrm{a}_{1}$ & $\mathrm{a}_{2}$ & $\mathrm{a}_{3}$ & $\mathrm{a}_{4}$ \\
\hline Without cracks & 44950 & -1.14 & 0.11 & -2.3 & \\
\hline With cracks & 0.0000248 & -0.84 & 0.14 & 1.07 & 1.11 \\
\hline
\end{tabular}

\section{Plastic deformation}

Due to plastic deformation, rutting is represented in HDM-4 as follows:

$\mathrm{RDPD}=\mathrm{K}_{\mathrm{rpd}} \cdot \mathrm{CDS}^{3} \cdot \mathrm{a}_{0} \cdot \mathrm{YE} 4 \cdot \mathrm{Sh}^{\mathrm{a}_{1}} \mathrm{HS}^{\mathrm{a}_{2}}$

(4)

$\triangle \mathrm{RDPD}$ - Gradual increase of plastic deformation in the year of analysis [mm]

$\mathrm{K}_{r p d}$ - calibration coefficient for plastic deformations

CDS- construction defect indicator

YE4- annual number of equivalent standard axes [million/lane]

Sh- velocity of heavy-duty vehicles $[\mathrm{km} / \mathrm{h}]$

HS- overall thickness of asphalt layers

$\mathrm{a}_{i}$ - model coefficients

Table 4. Values of the plastic deformation model coefficients

\begin{tabular}{|c|c|c|}
\hline $\mathbf{a}_{0}$ & $\mathbf{a}_{1}$ & $\mathbf{a} 2$ \\
\hline 2.46 & -0.78 & 0.71 \\
\hline
\end{tabular}

\section{Rutting as a result of wear and tear due to use of winter tyres}

The form of the model is given by the following equation:

$$
\mathrm{RDW}=\mathrm{K}_{\mathrm{rsw}}\left(\mathrm{a}_{0} \mathrm{PASS}^{\mathrm{a}_{1}} \mathrm{~W}^{\mathrm{a}_{2}} \mathrm{~S}^{\mathrm{a}_{3}} \mathrm{SALT}^{\mathrm{a}_{4}}\right)
$$

(5)

RDW - rutting due to the use of winter tyres in the analyzed year [mm] 
PASS - annual number of vehicles with winter tyres per direction

$\mathrm{S}$ - average velocity of traffic flow $[\mathrm{km} / \mathrm{h}]$

SALT - variable depending on whether salt is used in winter maintenance ( $\mathrm{SALT}=1$ no salt used; SALT $=2$ - salt usef)

$\mathrm{K}_{\mathrm{rsw}}$ - coefficient of calibration of the rutting method due to use of winter tyres

The model coefficients are given on the following table.

Table 5. Values of the coefficients of the plastic deformation model

\begin{tabular}{|c|c|c|c|c|c|}
\hline $\begin{array}{c}\text { Pavement } \\
\text { surface type }\end{array}$ & $\mathbf{a}_{0}$ & $\mathbf{a}_{1}$ & $\mathbf{a}_{2}$ & $\mathbf{a}_{3}$ & $\mathbf{a}_{4}$ \\
\hline All types & 0.000248 & 1 & -0.46 & 1.22 & 0.32 \\
\hline
\end{tabular}

\section{Overall rutting size}

The increase of rutting on annual level is given in the following equations:

$$
\begin{aligned}
& \text { If } \mathrm{AGE} 4 \leq 1 \Rightarrow \Delta \mathrm{RDM}=\mathrm{K}_{\mathrm{pd}}(\mathrm{RDO}+\Delta \mathrm{RDPD}+\Delta \mathrm{RDW}) \\
& \text { If } \mathrm{AGE} 4>1 \Rightarrow \Delta \mathrm{RDM}=\mathrm{K}_{\mathrm{pd}}(\Delta \mathrm{RDST}+\Delta \mathrm{RDPD}+\Delta \mathrm{RDW})
\end{aligned}
$$

AGE4 - age of the pavement regarding to the appearance of rutting, in years $\triangle \mathrm{RDM}$ - increase of the overall rutting size on annual level

$\mathrm{K}_{\mathrm{pd}}$ - calibration coefficient for all rutting

The overall rutting size is determined as follows:

$$
\mathrm{RDM}=\Delta \mathrm{RDM}+\mathrm{RD}_{\mathrm{a}}
$$

$\mathrm{RD}_{\mathrm{a}}$ - the overall rutting size at the beginning of the analyzed year

\section{Rutting calibration methodology}

Calibration of rutting progressing is a simple process of comparison of the envisaged and the existing rutting depth by establishing the relation between the geometric mean value of the measured rutting depth, ORDM and the geometric mean value of the rutting depth.

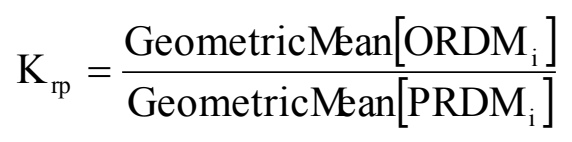

The rutting model calibration coefficient can be calculated by the sums of the logarithms of the measured and anticipated value

$$
\mathrm{K}_{\mathrm{rp}}=\frac{\sum\left(\log \mathrm{ORDM}_{\mathrm{i}}\right)}{\sum\left(\log \mathrm{PRDM}_{\mathrm{i}}\right)}
$$

$\mathrm{K}_{\mathrm{rp}}$ - coefficient of calibration of the rutting depth development

PRDM- rutting depth envisaged for the section

ORDM- measured rutting depth 
It must be noted that, as per the HDM recommendations on calibration level 2 it is sufficient to determine the coefficient of calibration of the overall rutting depth, whereas for level 3 of calibration, it is necessary to establish all coefficients of calibration of the individual rutting components $\left(\mathrm{K}_{\mathrm{rid}}, \mathrm{K}_{\mathrm{rpd}}, \mathrm{K}_{\mathrm{rst}}\right.$ И $\left.\mathrm{K}_{\mathrm{rsw}}\right)$

\section{Measuring of rutting depth}

Figure 1 gives the distribution of the increase, that is, the deepening of the rutting in the periods of analysis. The figure includes all rutting measures, except on sections where subsequent measurement indicates errors. The determined precision of rutting measuring is of $1 \mathrm{~mm}$. The average annual increase of the rutting is of $4.2 \mathrm{~mm}$ (standard deviation $=1$, and the changes vary from 0 to $7,4 \mathrm{~mm}$ /annually).

Remarks from this figure include the following:

- The annual increase of the rutting depth is within $4 \mathrm{~mm}$ for all intervals of analysis.

- The maximal annual increase of the rutting is of $11 \mathrm{~mm}$, and the minimal one is of

$2 \mathrm{~mm}$.

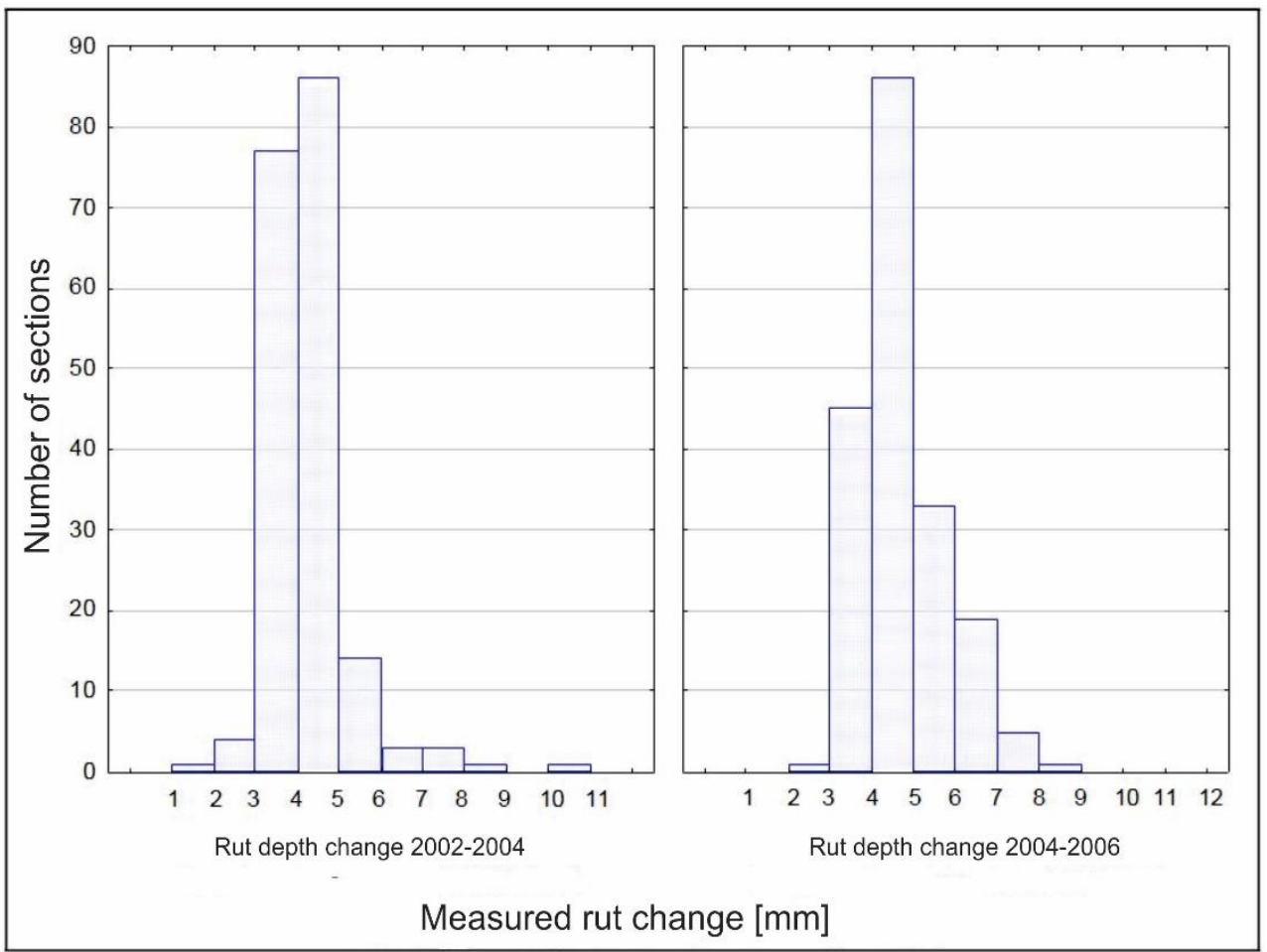

Fig. 1. Rutting increase distribution. Source: Public Enterprise of State Roads, 2002-2006

\section{Calibraiton of the HDM rutting model}

The format of the HDM-4 rutting model has been adopted within this research fort he establishment of the calibration coefficient. Figure 2 shows the change in the rutting depth for the non-calibrated model (the calibration coefficient being of 1).

Figures_2 and 3_indicate that there is no coincidence between the envisaged and the factual change of the rutting depth. The measured data demonstrate an annual change of $4 \mathrm{~mm}$, while the envisaged change of the rutting depth is of $2 \mathrm{~mm}$ per year. On the other hand, 
the non-calibrated model demonstrates that the depth of the rutting on the new pavements is of $20 \mathrm{~mm}$, which is not appropriate (the line of the envisaged and appeared depths and changes of the rutting begins at $20 \mathrm{~mm}$ ).

The acquired calibration coefficient as pursuant to the data obtained in Macedonia is given in Table 6 (equation 9).

Table 6. Calibration coefficient for rutting depth

\begin{tabular}{|c|c|c|}
\hline Type of data & Calibration coefficient $\left(\mathrm{K}_{\mathrm{pd}}\right)$ & Error function RMSE \\
\hline All data & 0.62 & 3657.7 \\
\hline
\end{tabular}

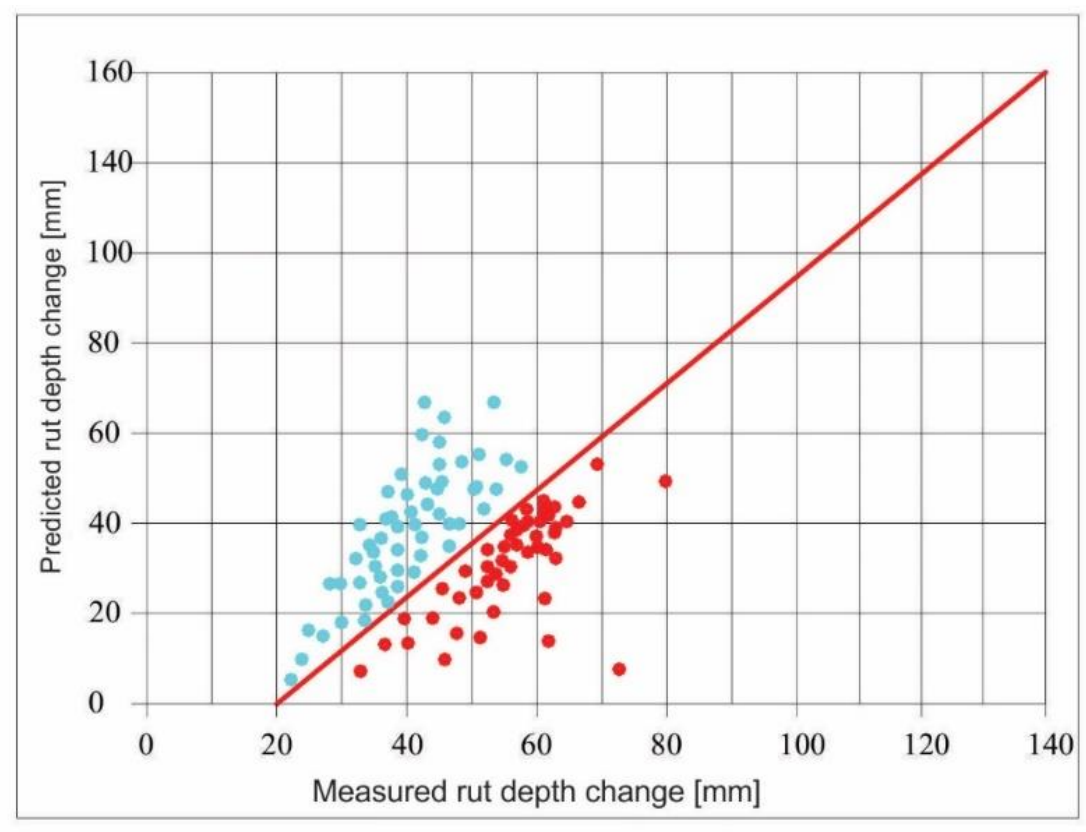

\section{- Predicted rut depth change [mm] \\ - Measured rut depth change [mm]}

Fig. 2. Relation between the predicted and measured change of rutting depth of the noncalibrated HDM model (Default model) Source: Own research

Figure 4 demonstrates that the relation between the measured and the real change of the rutting on annual level is already established by the new value of the calibration coefficient, $\mathrm{K}_{\mathrm{pd}}=0.62$.

Figure 5 shows that the new calibration coefficient establishes a practically ideal relation between the envisaged and the measured data on the rutting depth. It leads to the conclusion that the rutting development method with the adopted calibration coefficient can be used with high level of certainty.

Note:

The RMSE error function is obtained as a square root of the difference between the envisaged and the real values of the rutting. 


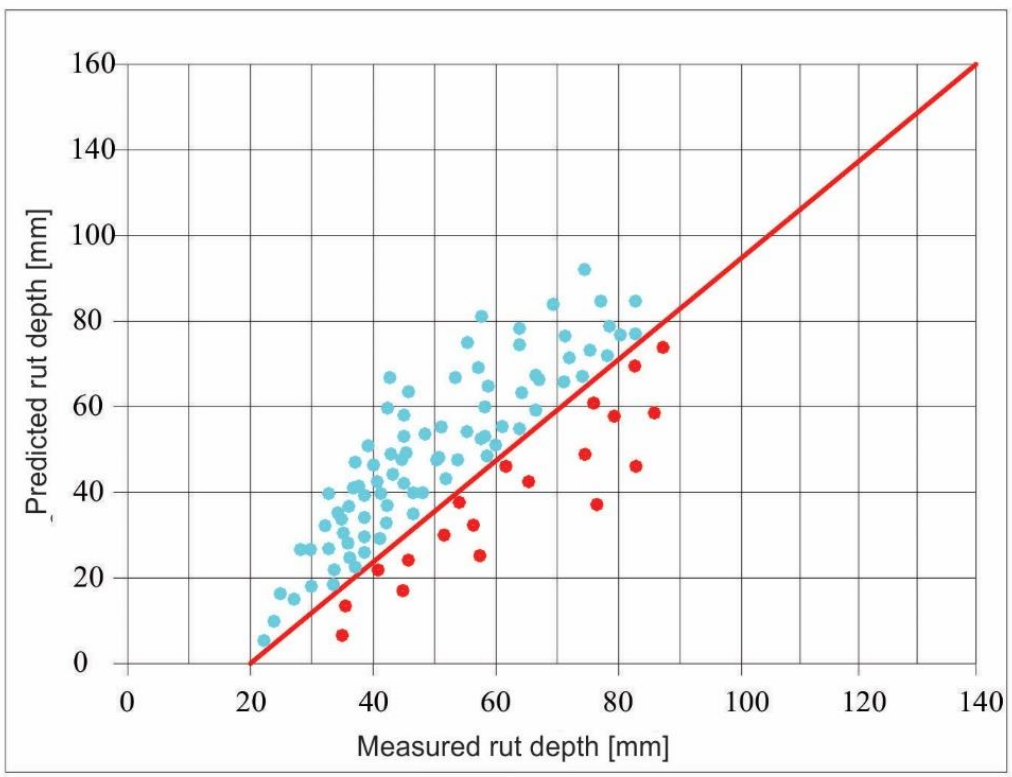

- Predicted rut depth [mm]

- Measured rut depth [mm]

Fig. 3. Relation between the envisaged and the measured rutting depth in the non-calibrated HDM model (Default model) Source: Own research

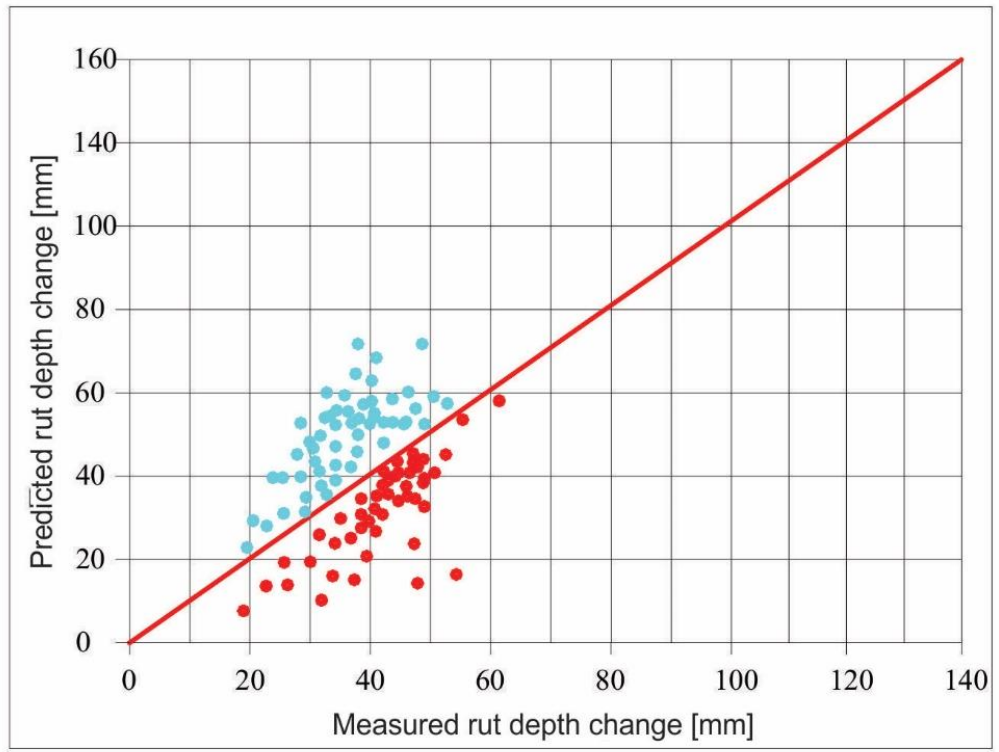

- Predicted rut depth change [mm]

- Measured rut depth change [mm]

Fig.. 4. Relation between the envisaged and measured change of the rutting depth in the calibrated HDM model. Source: Own research 


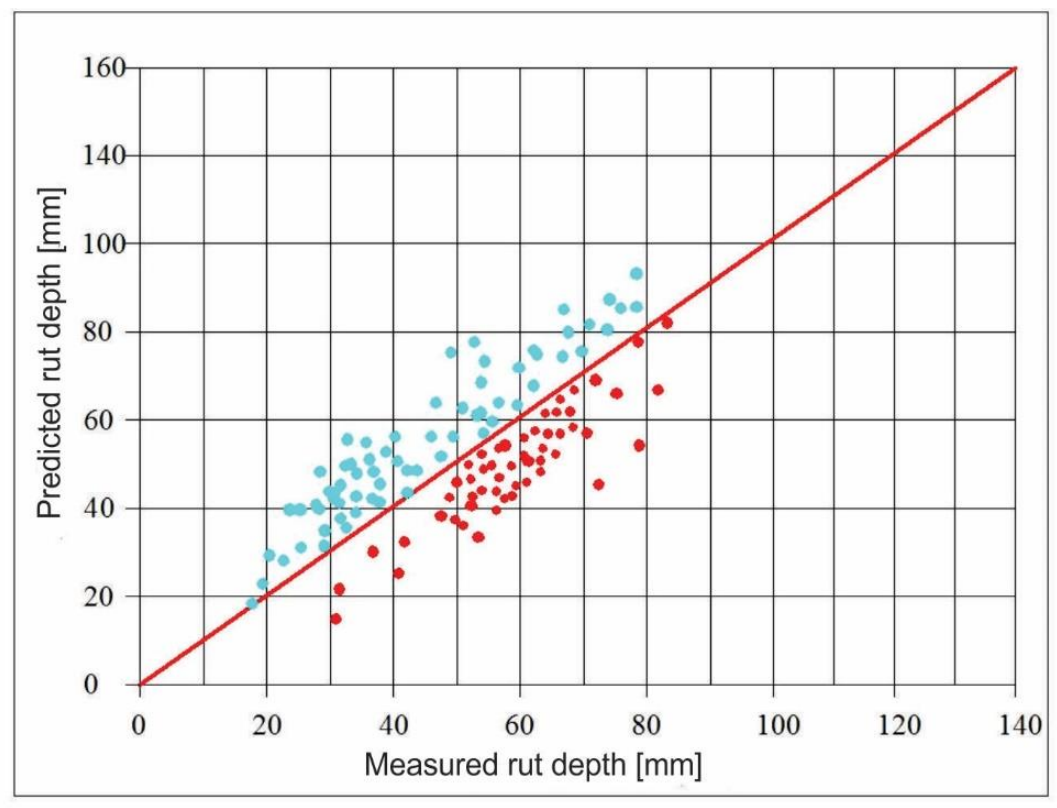

- Predicted rut depth [mm]

- Measured rut depth [mm]

Fig. 5. Comparison between the real and the envisaged rutting depth for the HDM-4 calibrated model. Source: Own research

It must be noted that some anticipations have been made regarding certain sizes on which there are not data.

Relative compacting: $\mathrm{COMP}=98 \%$

Crack percentage: $\mathrm{ACX}=3-17 \%$ for pavements aged from 10 to 20 years

Heavy-duty vehicle velocity: $\mathrm{S}_{\mathrm{h}}=50 \mathrm{~km} / \mathrm{h}$

Use of salt in winter maintenance : $\mathrm{SALT}=2$ (salt used)

Average traffic flow velocity: $\mathrm{S}=80 \mathrm{~km} / \mathrm{h}$

Average annual number of vehicles with winter tyres: PASS $=0.6 \mathrm{PGDS}$

\section{Conclusion}

The obtained calibration coefficient yields satisfactory results in comparison with the noncalibrated model. However, it must be noted that the research lacked new data on the rutting depth.

The only available data were the ones obtained in the period of 2002-2006 and 20102014. Despite the incompleteness of the measures conducted from 2006-2010, they were sufficient to offer control on the rutting development in the period from 2010 to 2014.

Nevertheless, more comprehensive analyses are necessary, within the period of at least 10 years as well as possible development of another model, which in fact is calibration of level 3 according to HDM. 


\section{References}

1. C.R. Bennett, Paterson, W.D.O., A Guide to the Calibration and Adaptation, HDM - 4. Volume 5, The Highway Development and Management Series, pp. $48-54$ (2000)

2. C.R. Bennett, Review of Experience Adapting the HDM Vehicle Operating Costs Model, Report to the International Study of Highway Development and Management Tools, pp. 78-92 (1997)

3. P.D. Cenek, Experimental Design for Determining Calibration Coefficients for HDMIII Field Deterioration Models incorporated in RIMS dTIMS, pp. 161-182 (1995)

4. W.D.O. Paterson, Scullion, T., Information Systems for Road Management: Draft Guidelines on System Design and Data Issues, World Bank, Infrastructure and Urban Development Department, pp. 202-216 (1990)

5. S. Ognjenovic, Calibration of the distress models of the pavement, Doctoral thesis, Faculty of Civil Engineering in Skopje, pp. 95-112 (2014)

6. G.T. Rohde, et. al. Henning, TFP, The Calibration and Use of HDM-4 Performance Models in a Pavement Management System, 4th International Conference on Managing Pavements. ICC Durban, (1998)

7. S., Rowshan et. al. Long-Term Pavement Performance Information Management System Data Users Guide, FHWA-RD-93-094. Federal Highway Administration. U.S. Department of Transportation. McLean, Virginia, (1993)

8. M. Y. Shahin, Pavement Management for Airports, Roads and Parking Lots, New York, (2005) 